\title{
Behavioral Finance and the Business Cycle
}

\author{
Ted E. Prince
}

Dr, Founder and CEO, Perth Leadership Institute, USA

\begin{abstract}
Despite a century of economic scholarship, economists and central banks still cannot predict recessions. Part of this problem is that modern economics is based on the idea that consumers and policy-makers make rational decisions. Economic models are based on lagging indicators of economic performance that compounds the problem of prediction.
\end{abstract}

Behavioral economics and finance are predicated on the assumption of mixed rationality; that is that many if not most decisions are not rational. In these disciplines, decisions are driven by innate and usually unconscious cognitive biases. This suggests that tracking cognitive biases may provide a new way to identify the phases of the business cycle. This has the added advantage that behavior is a leading indicator of outcome.

This article provides such an approach. It is based on a proprietary model of cognitive biases that identifies the Financial Signature ${ }^{\circledR}$ of economic actors. This concept is the sum of two key cognitive biases, the status quo bias and the illusion of control bias; these respectively are proxies for innovativeness and value-adding and thus gross margin and resource utilization or the level of indirect expenses by a consumer or manager.

The ratio of resource utilization to value-adding is the key metric. When this is high the economic environment is being driven by people with low business acumen who make bad economic decisions. When it is lower people with higher business acumen are driving collective economic decisions.

An environment where most decisions are driven by people with lower business acumen marks the peak of the business cycle, or the boom. Where the ratio is tipped towards people with higher business acumen, the environment is being driven by people with more favorable outcomes. This is the nadir or the business cycle. We can track this metric to predict accurately the phase of the business cycle and to identify if we are near to the top or bottom of the cycle.

The mechanisms to do this are a formal system of behavioral ratings, behavioral surveys and crowdsourcing. These might not necessarily replace current mechanisms for predicting business cycles, but would certainly complement them.

Keywords: behavioral finance, business cycle analysis, prediction of recessions, financial signature, business acumen.

JEL Classification: G02, E3, E32, C53.

(C) The Author, 2017. This article is published with open access at ARMG Publishing.

\section{Executive summary}

Part 1: Even the Nobelists cannot predict recessions

Current financial prediction and ratings approaches failed to prevent the last economic crisis, have exhausted analysts' imagination and creativity at devising new ways to predict recessions and the current stage of the business cycle.

\section{Part 2: Behavioral finance provides the new analytical model}

Traditional economics doesn't work any more for the tasks it is being given. Behavioral economics and finance need to take up this role. However even they have problems, but there are ready solutions to them.

\section{Part 3: Financial signature ${ }^{\circledR}$ is the key analytical construct}

There's a new game in town. It is called Financial Signature ${ }^{\circledR}$. This behavior can be measured and linked directly to financial and valuation outcomes. It's the missing link in business cycle prediction.

\section{Part 4: Leading to practical business cycle prediction products}

Using this framework we can implement practical behavioral finance products that for the first time provide a direct link between leaders, management teams and business cycle prediction. 
This solves the problems inherent in current economics and in business cycle analytical approaches.

\section{Part 1: Even the Nobelists cannot predict recessions}

\section{We cannot predict recessions}

We were in one of the longest economic expansions in history in the mid-2000s. So of course, the forecasters are jumping on the bandwagon to predict the next recession.

The only thing though: economists are tragically unsuccessful at predicting recessions. According to the IMF, in the 1990s private economists only predicted correctly 2 of 60 recessions one year in advance. The US Federal Reserve has never correctly predicted a recession until the country was actually in one. In a recent 2015 survey not a single major central bank could provide an example of a correct forecast. The survey covered the Federal Reserve, European Central Bank, BOE, BOJ and the Bank of Canada.

So much for the study of economics. The same resounding lack of success has also occurred in forecasting the outcome of M\&A transactions. ("Behavioral M\&A - Yahoo Needed It But Too Late Now"). So the failure applies to both macro- and micro-economics.

How do you explain the failure to predict recessions? The yield curve doesn't work - you know the old joke about it forecasting 12 of the past 2 recessions right? So it looks like when you use traditional economics and finance techniques they just don't work. Is there else something going on here? Do recessions occur as a result of something else that isn't economic so isn't captured in the normal economic data that all economies and countries use?

Many of you will be familiar with Occam's razor - take the most simple way you can to solve a problem. The ways that economists use are anything but. There is a phenomenon to be predicted so use the simplest explanation not the most complex. But so far no-one has come up with anything.

It reminds me of what was, at the time, seen as Einstein's biggest failure. He could see gravity at work but he couldn't explain why. So he invented something to explain it - the ether. For years, scientists saw it as somewhat dishonorable fudge until one day they discovered dark matter and dark energy. Voila he was right. Occam's razor worked again!

So is there a parallel insight in economics? We need look no further than grand old man Lord Keynes. His explanation was simple - animal spirits. But this has always been seen as whimsical, again a dishonorable fudge that is unscientific because it cannot be defined and measured, except by surveys of consumer sentiment that don't work anyway, at least not in advance.

So what might animal spirits be? Let's say there's something actually there. What is the essence of animals in the human view that might give us a better handle on them? Here's a stab - irrationality. Could animal spirits refer to the level of irrationality in our collective thought compared with the level of rationality? Could the changing balance between the two explain when things go off the rails?

If it could it brings us to some exciting insights. First the Grand Old Man had already thought of behavioral economics and finance before Tversky and Kahneman. He had already understood that we cannot just explain economic phenomena by reference to rational human decision-making. He understood that sometimes our decisions will go into a period of irrational responses like irrational exuberance and then irrational depression that will overturn the economic system until we get our wits back again.

Second Keynes probably understood very well that irrationality was a prime mover, but he could not figure out how to define and measure it. It was certainly beyond the scientific levels of the times, just as it still probably is now. So he gave it an airy answer just like Einstein. But that doesn't mean he was wrong. Far from it.

The biggest thing he would have had to explain was, even if you could define and measure the level of irrationality in the collective decisions of consumers and business, why did it happen just at that particular time? Why not all the time? Or none? What caused it to happen just at that particular time and no other? Why does it happen every 5 years or 7 ? Why is there an economic cycle anyway? Or super cycle? What actually precipitates it?

Later in this paper we are going to offer a model that addresses these issues. 


\section{Methods to assess and predict systemic market risk do not work}

The last 50 years have seen the rise of new approaches to dealing with risk in financial markets. Broadly speaking risk approaches have undergone three phases:

$>$ Phase 1. Conventional statistical risk approaches;

$>$ Phase 2. Game theory approaches;

> Phase 3. "Quant" approaches based on methods from the physical sciences.

The Phase 1 approach relied on conventional statistical analysis to analyze markets and to draw inferences from them. It was based on conventional Gaussian approaches with predefined normal-like distributions. Experience has shown that conventional statistical approaches are of very limited utility in predicting the strategic, as distinct from the tactical, direction of markets and hence they have fallen largely into disuse for most real- world financial market risk analysis.

The Phase 2 game theory approach was adopted in an effort to address the failures of conventional statistical approaches. Game theory approaches are still in use but mainly in the academic world rather than in the markets. They may be of use in ex post facto explanations of market movements, but again are of little to no use in predicting market movements and market risk.

The Phase 3 approach, commonly known as the quant approach, is widely used in financial services companies. Based on mathematical methods and concepts from the physical sciences, the quant approach develops algorithms within a dynamic context in order to exploit market inefficiencies and to profit from them.

In the short-term these methods can work well. They work best in working within the current market parameters and when fundamental market conditions do not change much. They also work well when most market players are using different risk assessment approaches.

However when market assessment and risk approaches come to be copied across most market players, these methods tend to break down in managing system and strategic, as distinct from non-systemic and tactical market risk. Stated differently, once most players use the same methods to assess risk - as has been the case in the last few years - and when risk assessment essentially becomes a mono-culture, then quant methods break down and become effectively of little or no value in trying to protect against systemic risk.

This was demonstrated with crystal clarity by the failure of Long-Term Capital Management in 1998. LTCM was founded by Nobel Prize winners in economics and its methods were based on the quant approach.

The credit crisis of 2008-2010 ("The Great Recession") was also not predicted by the quants. It forms yet another case- study in the failure of Phase 3 approaches to assessing and predicting market risk.

All three phases of financial risk management have shared one common assumption. That is, that financial risk management is best assessed by technical experts who possess deep knowledge of various branches of mathematics and statistics. This corps of expert analysts has been viewed as elite whose methods are not capable of being shared and used generally by their non-technical colleagues.

This implication of technical preciosity has led to the presumption that expertise and success in market financial risk management can derive only from a small group of people whose technical knowledge is rare and unique. We call this the Boffin model of market financial risk management.

The Boffin model entrusts the responsibility of risk assessment to technical experts who have PhDs in mathematics and the physical sciences which is seen as being able to generate insights that will accurately be able to manage market risk.

The Boffin model is a modern version of the theory that led the British to hire Latin scholars to run the British Empire on the assumption that these linguistic and classical skills would generate insights that would lead them to have superior success in managing unknown foreign peoples. It is also the same process that led to the view that psycho- analysts grounded in Jungian and Freudian theory would provide insights that could lead, variously, to solving mental and emotional problems in people and, most recently, that would be able to generate effective leaders based on these insights.

As we shall see, the Boffin model has effectively displaced other models of risk management which may well have been vastly more effective at assessing and predicting directions in financial markets. This conclusion has very important implications for leadership development, not only in financial services 
companies, but also other companies which need also to make predictions of market financial risk in order for their own businesses to have long-term sustainability.

\section{A high level of business literacy may actually increase market risk}

The reigning assumption in the corporate world is that high levels of business literacy will reduce market risk. By "business literacy" we refer to the possession of business qualifications such as an MBA or more technical skills in economics or finance.

Yet a body of data is emerging which suggest otherwise. In his pioneering research, Jay Zagorsky (2007, 489-501) at the University of Ohio has shown from US census data that high IQ is directly correlated with income but within certain IQ ranges is actually inversely correlated with wealth. Data from the Perth Leadership Institute suggest that possession of high academic or professional qualifications is inversely related to business acumen. This includes the possession of a business degree including an MBA.

Clearly the possession of an MBA does not confer any advantages in terms of an ability to make money for their companies otherwise we would see a systematic bias for MBAs to be more successful than non-MBAs in running companies. This is demonstrably not the case.

Many companies are conducting what they call "business acumen" courses as part of their leadership development programs. These are usually courses which teach basic financial skills such as reading financial statements.

These courses should properly be called "business literacy" courses since they signally do not assess for business acumen or teach participants what it is and how to improve it.

Financial and non-financial services companies are both adopting this basically erroneous approach. However, it does demonstrate that many companies are slowly becoming aware of the fact that they need to formally address business acumen in their leadership development approaches, even if they have not yet developed the right vehicles to achieve this.

\section{The quant approach is a major contributor to systemic market risk}

The role of the quants in the current market cycle has been major and its failure is increasingly evident. The Long-term Capital Management fiasco led to fears of systemic risk and breakdown and only intervention by the Federal Reserve Bank saved the day.

In the current crisis, quants also were a major contributor due to group think which led to all taking similar actions and all similarly failing due to the same factors. This group failure was exacerbated by analysts in the ratings companies, whose technical risk models, derived from quantitative methods of their own making, failed to anticipate the radical risk represented by the subprime sector in the first place.

In addition to group pressures, the quant approaches failed due to their reliance on psychological processes which were assumed to be analogous to social processes, an assumption which turned out to be invalid. In effect the quants did not integrate into their models behavioral approaches, specifically behavioral finance approaches, which could have revealed that the level of market risk was increasing rapidly as business acumen levels declined.

The quants were not able to do this because they themselves were a key part of the group of players who had reduced levels of business acumen, that is, they were not independent observers at all but a key group in the mix of players that caused the market problem in the first place.

The quant models assumed that they were independent spectators who do not affect market risk. What they and the leaders of many of the financial services firms have not appreciated is that their risk assessors are key actors in generating and exacerbating market risk. As long as they continue to operate on this assumption, market crises, once corrected will return again.

In effect the Boffin model of market risk actually is one of the key causes of market risk and market crises. As long as financial services firms keep this model, they will continue to generate market volatility and systemic risk without ever actually realizing it.

\section{Lack of financial self-awareness is the single biggest contributor to market risk}

Many, arguably even most, executives have reached their current high position at least partly due to some level of happenstance or luck. This can include being in companies that are doing well and from which they 
garner an image of success, even though it had little or nothing to do with them. This is known as the Halo Effect.

Included in this group are executives that have reached their position due to being in the right place at the right time, having the right mentor, backing the right horse and so on.

Of course, executives who reach their high positions rarely attribute their success to luck. The vast majority will attribute their success to their skill and, in some cases, to their superior smarts and genius. However many of these executives will reach a high position in which they fail and which leads to their demise, in many forms.

By definition, executives who attend leadership development programs are still on their way up and still around so they will invariably have not reached such a defining moment when they undergo such programs. Thus the effect of these programs is usually to reinforce the conclusion that the success of many of these executives - but not all - is due to their own skill rather than to other influences. Recent books by Nassim Taleb underscore this phenomenon (Taleb Nasim).

In the financial services industry in particular, this phenomenon results in senior leaders being reinforced in their belief that they have reached their level of financial performance due to their own skills and knowledge, rather than having being the unwitting beneficiary of the process in which a rising tide lifts all boats. This translates into managers and executives believing that they have mastered the elements of risk assessment and prediction when in fact nothing could be further from the truth. The Boffin approach tends to strongly reinforce their confidence in their own skill in managing risk, even if they do not have any.

Leadership development, through formal programs or informal approaches, perpetuates this systematic weakening of risk assessment by not teaching leaders about this phenomenon. Leadership development programs which do not attempt to counteract the phenomenon of denial of luck are in fact inadvertently adding to the market risk faced by their company by not teaching their people about the role of their own self-denying behavior in increasing market risk.

Leadership development, whether formal or informal, needs to systematically introduce the topic of the role of business acumen and luck in financial behavior so that market players can objectively understand how their own behavior actually increases market risk so that they can implement mechanisms to counter-act this in their programs.

The Great Recession owed much to the assumption by executives in the financial services companies in particular, and companies in general, that their formal risk assessment processes were technically sound and that their own executives were not part of the process that generates risk.

In effect, lack of self-awareness of business acumen or luck on the part of executives who play any part whatsoever in the development, distribution or marketing, and the acquisition of financial products is itself a major contributor to the generation of high risk levels in the market.

Furthermore, this process is not just one that impacts financial services companies. Buyers of their services including companies that invest in their products, use them for financial advice (hedging, $\mathrm{M} \& \mathrm{~A}$, financial structuring etc.) also will be subject to the same phenomenon and will also be adversely impacted by their lack of awareness of this factor which will lead to them facing increasing systemic risk through their acquisition of financial services and products from financial services firms such as derivatives, CDOs and the like.

In effect, corporate consumers of financial services products generated by the financial services industry will themselves be as much as a contributor to the heightening of market risk because of their lack of financial self-awareness as will those financial services players who develop market products and distribute them.

\section{...leads to financial derailment for executives}

Marshall Goldsmith has recently published a book entitled: "What Got You Here Won't Get You There" (Goldsmith Marshall and Reiter Mark, 2007). This is the restatement of a widely held thesis in the leadership education community that states that once you start getting near general management levels, you need to radically change your style to get any further, even to the point of doing things in the opposite way you did them before you started reaching such exalted heights.

We can all agree with this proposition. However it has not been one that has been applied in the strictly financial and risk assessment area. Roughly stated, we can restate the Goldsmith proposition in the following way: 
In the risk assessment area, the financial behaviors that were effective at a lower level will be ineffective at your new level. This is akin to the Keynesian Error of composition in which more savings actually leads to less investment, not more.

In the market risk world we can restate this as saying that the more financial services professionals that apply the same risk approaches at senior levels as they did at more junior levels, the more market risk will increase, rather than be reduced. One implication of this is that the more quants there are in any market, the more market risk will increase.

The reason for this is that they are all using the same models which do not take into account the impact on market risk of the people whose job is actually to assess it. In other words, the less these managers take into account their own impact on the system, the more market risk will actually increase.

This is an area in which all companies, but particularly financial services companies need to educate their staff, right from the junior professionals to the most senior ones, and particularly these charged specifically with the responsibility of assessing and predicting market risk. If this is not done, then market risk will continue to increase in the cyclical way we have described earlier and the system will regularly experience financial and credit crises.

The immediate implication for executives who are not aware of this is that they will likely fail when they get into a more senior position when the market hits problems. Lack of financial behavioral self-awareness will lead to the financial derailment of many senior managers and executives.

This will continue to lead to wasteful loss of otherwise talented executives and a loss of good human capital and corporate memory, with its attendant effects of inadvertently again increasing market risk. Leadership development can address this major problem by ensuring that this issue is formally addressed in leadership development programs and interventions and in executive retreats and seminars on market risk.

\section{....and to valuation derailment of companies}

When financial derailment of executives occurs, it will often tend to lead to valuation derailment of the company. This occurs due to the ouster of the CEO and much of the executive team and the accompanying management disruption. Since the CEO may have been fired as an example, rather than having been the true reason for the company's valuation problems, there can be no guarantee that the next person will do any better, at least over the longer-term.

Thus financial derailment of executives due to low levels of business acumen can easily lead to valuation derailment of their companies. And if this occurs across a number of companies in an industry, say financial services companies as is happening now, this can also lead to increased levels of systemic risk.

It will also lead to changes in the competitive landscape as companies adjust to the differing levels of business acumen of the incoming executives. In effect, the levels of business acumen of the executives of the companies that constitute an industry drive the relative competitive positions of the industry's players. Those who have high levels of business acumen do better than those who do not. Thus the financial derailment of executives can lead to a chain of effects stretching up to the valuation derailment of companies and changes in competitive positioning of the companies in an industry.

Changes in an industry structure due to differing levels of business acumen of its corporate players may lead to more or less risk depending on the level of maturity of the industry and how many of the companies have high or low levels of business acumen. In a mature industry, more often this will lead to increased risk as innovative managers are screened out; witness the auto industry in the US. What we can say though is that levels of business acumen are intimately linked to industry structure, market maturity and the overall level of market risk.

Financial services companies need to understand these links in order to do their jobs better. Only by understanding these links can they become better at their core job, managing and profiting from market risk.

\section{Part 2: Behavioral finance provides the new analysis model}

\section{Shareholders want to know: "Where's the beef?"}

Leadership in modern organizations is required to increase profitability and valuation. This applies to both public and private companies alike. Scarce capital is used by these organizations and the ability to make it more effective is a key requirement of modern leadership. Leaders who do not do this are routinely 
removed in order to find leaders who can. So leaders must drive better financial and valuation outcomes in order to be better leaders.

Yet the classical leadership corpus signally fails to do this. Leadership assessments focus on interpersonal skills and certain behavioral competencies. While these are relevant to leadership, they do not define its success in modern organizations. Success in modern organizations is ultimately financial and valuation outcome. To be precise, if an organization gets a better valuation outcome than its competitors, then its leadership has performed better. Nothing else counts as long as the organization operates ethically and is reasonably managed.

The major criteria in the classical leadership canon for leadership success are interpersonal, team and organizational functioning. Thus derives from their intellectual bases which are psychoanalytic, sociological and anthropological. Basically they look to harmony rather than outcome. They tend to be employee- rather than shareholder-focused. So they lack the intellectual underpinnings which focus on the building of financial valuation and maximization of capital creation.

The overwhelming problem with modern leadership approaches is the failure to link directly with leadership outcomes, defined in financial and valuation terms. The classical leadership corpus cannot help this since it has intellectual foundations that are largely unrelated.

In order to build the necessary linkages, we need to turn to the disciplines of economics and finance. These are disciplines which experts in conventional leadership and human resources are generally uncomfortable with. This probably explains at least partially why these disciplines have not been enlisted. So we shall turn our attention to them now to see to what extent they can meet the requirement of linking leadership and financial and valuation outcomes.

\section{But traditional economics and finance assume perfect rationality}

Classical economics has a history dating back to the $19^{\text {th }}$ century. The classical economists ranging from Adam Smith to Keynes built formal models based on a very particular psychological platform. That platform assumed that individuals and corporations are rational economic actors. This allows a sophisticated structure of models to be built.

At the microeconomic level it allows for the development of utility theory. This in turn allows for the development of choice theory for both consumers and corporations involving indifference curves and the like. The assumption of rational economic actors underlies the full range of microcosmic topics ranging from pricing, demand theory, consumer choice and more latterly decision and game theory. Latterly these theories have been extended to modern work in the areas of options and options prices, derivatives and synthetics

At the macroeconomic level, the assumption of rationality allows for the development of theories regarding a wide variety of topics including interest rates, money supply, and consumer demand. These in turn have been built up into models of growth which incorporate linkages between investment and consumer behaviors, savings and investment, interest rates and money supply. It is from this base that the idea of the efficient market hypothesis arises. All of these models depend on the assumption of rationality to work.

Economists have always known and accepted that these theories are an approximation to the real world. The models work fairly well when conditions do not change much. However it has become increasingly clear that the classical economic models do not work at all in the following cases:

When conditions change significantly;

$>$ In predicting major changes in corporate valuation;

$>$ In predicting macroeconomic inflection points and crises.

It is increasingly being seen that classical economics tends to work best when conditions do not change much, and when rational behaviors dominate the market. When these conditions are infringed, then classical economics and finance break down and cannot predict the outcome

In this sense, classical economics and finance are reminiscent of classical leadership models. In both, rationality is the basis for the model to work. When irrationality enters, the models break down. In both cases the models cannot predict what happens if most behavior is not rational. So the classical theories have major restrictions that limit them to only being valid in particular, relative narrow situations.

That is one reason why leadership approaches have not been able to incorporate classical economics and finance in order to link financial and business outcomes. These classical disciplines assume a level of rationality that is just unrealistic in leadership and thus prevents them being used for real-life leadership 
situations. For economics and finance to play a part in linking leadership with business outcomes, they must be able to able to address irrationality in decision-making.

\section{Irrationality is now being addressed through new behavioral disciplines}

We have always known that leaders and decision- makers have biases. The trouble is that they are difficult to model in particular situations. We may know that a leader tends to under-spend or over-spend, but predicting that in advance for a particular leader or company is difficult and requires models that have only recently commenced development.

We know that there are numerous other types of biases that affect decision-making. However these had never been cataloged or their effects formally described. So although theorists knew that rationality was not really realistic, a formal platform had never been developed to model those biases.

The issue has been how to link irrationality - or to be more accurate, mixed rationality - in decisionmaking with economic and financial outcomes.

The first steps in this process have been made with the emergence of the new disciplines of behavioral economics and finance. These disciplines formally relax or drop the assumption of rationality in building models of economics and financial phenomena. For the first time we now have a language and models that link financial outcomes to real decision-making in the real world.

This allows us for the first time to formally link decision-making that is not necessarily rational to financial and business outcomes. Since this is what leaders do, we now have for the first time a set of models that can use be used to describe and predict leadership behaviors and outcomes, in business and financial terms.

\section{Behavioral economics \& finance open up a new analytical approach}

Their Newness Explains Why Leadership Approaches Haven't Caught on Yet: The field of behavioral economics and finance can be said to have received formal recognition of their intellectual coming-of-age with the award of the 2002 Nobel Prize for economics to Daniel Kahneman of Princeton University for his work into behavioral economics.

Research into this field commenced in the 1960s with work by Nobelist Herbert Simon and expanded in the 1970s with the development of what is called prospect theory. Prospect theory is a theory of decisionmaking where decisions have uncertain outcomes and people have different ways of evaluating gains and losses. These decisions are not necessarily financial in nature although much of the work that surrounds them is concerned with economics and finance.

The research has been motivated by the increasing divergence between prediction and reality in the fields of economics and finance. It had become increasingly clear that economies and finance were not approximating reality and that a new approach was needed.

For the first time, what we term "irrationality" has been formally opened to research and investigation in the fields of economies and finance. These new fields provide comprehensive explanations and models as to what constitutes irrationality in decision- making and show how it leads to totally different types of economic and financial outcomes to those predicted by classical theories.

\section{Behavioral disciplines explain much that was hitherto inexplicable}

The new behavioral disciplines have far-reaching ramifications for most business and economic areas. They impact decision-making, human resources, strategy, marketing, consumer choice, advertising, talent development and human resources, investor behavior, and stock market behaviors to mention just a few. So far the impact is at an early stage since the fields are still very new and practitioners of these disciplines are only slowly coming to grips with their many implications.

McKinsey Quarterly has carried an article on this subject (Lovallo Dan and Sibony Olivier, 2010). They cite some of the problems that are caused by the lack of understanding of behavioral strategy. These include failed mergers and acquisitions, large projects usually being over-budget and strategies usually ignoring competitive responses or getting them badly wrong.

McKinsey has conducted some fascinating research on this issue. This research concludes that, contrary to what one might expect "good analysis in the hands of managers won't naturally yield good decisions..." (Lovallo Dan and Sibony Olivier, 2010). This of course flies in the face of conventional approaches that 
assume if we are smart, reasonably educated and have the right data, we will have a very good chance of making a good decision that will have a beneficial outcome. It explains why, to the contrary, so many decisions at all levels of management, informed by the best analysis possible, so often yield poor outcomes.

As one might expect from a consultancy that focuses on strategy, the McKinsey research has a lot to say about the implications of behavioral disciplines for strategy development. Their work suggests that cognitive biases affect the smartest executives in the most important companies.

For leadership this has critical implications too. It suggests that most leaders are unaware of their biases and therefore are not in a position to compensate for them. In hiring, developing and promoting leaders, those who participate in these processes cannot identify these biases and predict their impact on the quality of leadership of the managers they are promoting.

In sum, if anyone ever wanted a good explanation why so many leaders fail, and why so many boards and leadership experts tend to make so many bad hires, one has only to look at the previous formally unrecognized issue of cognitive biases.

The behavioral disciplines are not just about finance and economics; they are ultimately about leadership and how flawed the outcomes of leadership are likely to be. That these outcomes can also be measured in financial and economic terms is a bonus, but the behavioral disciplines provide a new perspective on any type of decision, be it economic and financial or otherwise.

\section{In categorizing types of cognitive bias}

In their new theory, termed prospect theory, Kahneman and Tversky in the late 1970s identified and set out a number of cognitive biases that routinely impact decisions, both financial and otherwise. What they pointed out was that these biases had never been taken into account in classical economics and finance. The existence of these biases meant that the rational decisions assumed by classical theorists were very unlikely in the case of many if not most decisions.

It is not the intention of this Article to provide a primer on behavioral economics and behavioral finance. However it will help to provide some examples of these cognitive biases. In their book, some of the principal biases mentioned were as follows:

$>$ Framing effects: The way a problem or decision is presented to the decision maker will affect their action.

> Sunk cost fallacy: The tendency to continue to invest in something, even if it is a hopeless case.

$>$ Status quo bias: people prefer that things remain the same, or that things change as little as possible, if they absolutely must be altered.

$>$ Endowment effect: people value a good or service more once their property right to it has been established.

$>$ Loss aversion: people's tendency to strongly prefer avoiding losses to acquiring gains. Some studies suggest that losses are twice as powerful, psychologically, as gains.

$>$ Anchoring effect: the tendency to rely too heavily, or "anchor," on a past reference or on one trait or piece of information when making decisions.

$>$ Overconfidence effect: excessive confidence in one's own answers to questions. For example, for certain types of question, answers that people rate as "99\% certain" turn out to be wrong $40 \%$ of the time.

$>$ Survivorship bias: concentrating on the people or things that "survived" some process and ignoring those that didn't, or arguing that a strategy is effective given the winners, while ignoring the large amount of losers.

There are numerous other cognitive biases that have been identified. These biases are not just ones that have been observed. All of them have been tested through actual experiment so that the situation can be controlled scientifically. So the existence of these biases has been scientifically confirmed, measured and manipulated to see their effects in many different situations.

It will be clear that these cognitive biases operate within the decision-making environment of any company. So these cognitive biases must be a key driver of problems in these companies. They are therefore an important microeconomic factor. Of course, this also means that they are a crucial factor in leadership, talent management and talent development for any company.

Since these biases operate in all companies and in all organizations, including in nonprofits and governmental organizations, they also operate at the macroeconomic level. This means that they impact demand and supply 
at the macroeconomic level, and in the areas of growth, trade and investment. Again this impacts leadership at the national levels as well as the international levels.

It does not take a great leap of imagination to see that these cognitive biases are crucial in assessing and studying leaders and the outcome of the decisions. Yet none of this way of thinking has yet impacted financial and valuation analytical approaches.

This is probably due to two main factors. First, this is a relatively new field of study. Second many leadership experts feel uncomfortable with business issues and particularly with economics and finance so they stay away from these topics. Thirdly, most financial and business analysts are not familiar with and are uncomfortable with behavioral and psychometric approaches. Clearly this will have to change if financial approaches are to keep up with the times.

\section{But the new behavioral models are far from perfect}

Some Key Issues Not Yet Addressed: So the new behavioral models open up vast new swathes of territory not only in the economic and financial arena, but also in the arenas of decision-making, leadership, talent management and development. They also provide new perspective on strategy development and implementation. They suggest that too much information can be as dangerous as too little. They provide new ways to improve decisions and to optimize their outcomes in business terms.

But as with any new discipline, they still leave vast swathes of problems unaddressed. This is not a criticism; it is just to state that now these new disciplines have opened up new territory for investigation, they have also allowed new questions to be asked which so far have not been answered and in some cases cannot be answered without more advances in theory and more data from experience. This is the case with the behavioral disciplines.

Some of the problems that are not addressed by behavioral economics and fiancé are the following:

The Problem of Individual Prediction: The behavioral disciplines have identified a rich catalog of cognitive biases and described their effects. Although these effects work at the level of the individual, we can only use them predictively at the level of the group. The new behavioral disciplines provide no model that allows us to predict how these cognitive biases will act in the case of a specific individual, a specific team or a specific company.

We term this problem, the "atomism" problem. We can predict at the level of the organization, say the country, or a large group of consumers. But we cannot make predictions at the level of the individual social atom, the individual, the consumer, the manager, the specific team in a specific company. For the behavioral disciplines to be seen to be more than an academic exercise, they need to address and provide solutions to this problem.

Predicting Precise Business Outcomes: Even more importantly these do not show the actual financial outcome of these cognitive biases for any individual, team or company on business outcomes such as profitability or valuation. Yet it is precisely these issues that are of most interest and utility to shareholders, investors and economists who wish to predict these matters so that the work can have real-world relevance.

We term this problem the "outcome" problem. We need to be able to do more than just say that a particular cognitive bias will distort the outcome of a decision. We need to be able to say how this will happen in practice. In particular we need to be able to couch the outcome in measurable and quantitative terms that are part of the financial and valuation metrics of a company so that we can link behaviors and cognitive biases directly to profitability and capital creation or consumption.

The Problem of Non-Financial Decisions: Not all or even most decisions have an explicit financial element; yet the behavioral disciplines couch their terminology in financial and economic terms, as they must given their intellectual background.

Yet it is clear that cognitive biases impact non-financial and non-economic outcomes just as much as they do financial and economic outcomes. The behavioral disciplines have done much behavioral disciplines started their good work by focusing on consumers and investors. It was only later that they broadened their focus to corporate managers but even then the focus was on corporate financial managers rather than all managers.

But the work has not yet broadened its reach to actors who are explicitly focused on non- financial issues such as corporate managers of sales for example. Yet it is clear that these players also have an impact on business outcomes through the impact of their cognitive biases. Just because they are not primary initiators 
of investment or $\mathrm{P} \& \mathrm{~L}$ managers does not mean they do not have an impact on the overall $\mathrm{P} \& \mathrm{~L}$ of the organization, or on its valuation.

But the behavioral disciplines are not so comfortable in the non-financial arenas and so have tended to avoid these issues. So these new disciplines so far are more oriented to actors that are explicitly economic and financial actors which limits the applicability of the research to some of the most intriguing and important issues in corporate decision- making and finance.

Atomism and Outcome Problems Most Important: Of the above, the atomism and outcome problems are the two most important. This is because they prevent the theory being operationalized so that it can be used in practice to improve the outcome of decisions. If the aim of a scientific theory is control, then the behavioral decisions are still some way away from this goal. Later in this article we will show some later developments that specifically address these problems and provide some solutions.

\section{Neuroscience and neuro-economics provide atomistic view}

As behavioral economics and finance have emerged and expanded, so has the demand for other types of investigations that would provide increased knowledge on behavior, decision-making and in particular economic and financial decision-making. This new research addresses the issue of the individual level headon and provides an atomistic perspective that advances the understanding of behaviors at the individual level.

This research relies on MRI, magnetic resonance imaging. This allows scientist to look a brain in real-time to see precisely which areas are impacted when the brain is carrying out certain activities which the subject has been told to think about in advance. These include making decisions on certain matters, or thinking about certain things.

This research aims to elucidate the physical and physiological mechanisms that are involved when decisions are being made or when certain types of thoughts are being played out. The aim is not only to look at physical brain locations involved, but also to look at the types, intensity and frequency of brain waves and other impactors such as changes in brain chemicals and neurotransmitters.

The more general science has been termed neuroscience. This broader approach investigates thoughts, decisions and emotions. The narrower research is called neuroeconomics. The aim of this science is to elucidate physiological mechanisms involved when the brain is making economic and financial decisions and making choices.

Like neuroscience, neuroeconomics can be experimental in nature so that the fully range of scientific tools can be made and hypotheses investigated. Experimental economics can be combined with neuroeconomics to gain a much deeper appreciation of the biological mechanism involved in economics and financial decisions.

This research also extends to neurochemistry and in particular to the neurochemical oxytocin, the so called love chemical. This research also looks the impact of certain neurochemicals on behaviors, particularly trusting behaviors and their impact in human interactions. While oxytocin has been the hot topic, it is likely that this is just one of a class of neurochemicals that mediate behaviors including financial and economic behaviors and also the mechanisms of choice.

These new channels of research are also opening up new perspectives on economics, finance and decisionmaking, this time from a biological and physiological perspective. However, we need to note that these are not cognitive but "wetware" models that give us physical rather than cognitive explanations of decisionmaking and choice.

The wetware models do address the atomism issue. They add to the knowledge concerning how to make predictions at the level of the individual, something that cannot do with current behavioral economics and finance. But these approaches still do not allow us to make predictions about business outcomes, a key requirement for relevance and use in the corporate world.

\section{Recent empirical studies address behavior and business outcome}

However there is increasing work which investigates the decision-making characteristics of CEOs and managers and links these to their impact on company financial and valuation performance. One pioneering piece of research by Marianne Bertrand and Antoinette Scholar (2003) specifically looks at the managerial characteristics of CEOs to investigate their impact on a wide range of corporate financial variables. 
This work finds a high correlation between the two. The authors find that these managerial behaviors can be characterized as distinctive financial styles that have a characteristic and unique impact on company financial metrics and performance. The authors specially note that they are departing from the usual economic approach, which is to look at financial outcomes at a firm, industry or market level.

In other words, this study specifically addresses the issues of atomism and outcome in leadership behaviors. This work finds high correlations between the two. The literature now shows that the issue of managerial financial style is real and can be correlated statistically with characteristic financial and valuation outcomes.

More recent research shows the consistency of financial styles between personal and corporate financial choices on the issue of personal and corporate leverage, again linking financial behaviors with financial outcomes (Cronqvist H, Makhija A.K., Scott E. Yonker S.E., 2010). It shows that CEOs' personal financial behavior is at least partially predictive of their companies' financial performance.

In sum, this recent empirical work addresses the issue of business outcome more comprehensively than has been done with the classical works of behavioral economics and finance. The problem is that there are no theoretical constructs or models underlying the behavioral side of the problem.

So while wetware and CEO studies address respectively atomism and business outcome, neither address both and link the atomistic level directly with business outcomes in a formal model that simultaneously addresses both. But that issue has now recently been addressed as we shall show in the final part of this paper.

\section{Leadership training and business metrics}

Leadership training often incorporates the words "business outcomes". However the problem is that it rarely shows the direct linkages between behavior and business outcomes. Most work on this tends to show that a high level of investment in training leads to positive business outcomes. However it does not show any direct linkage. So a lot of this research lacks credibility since it cannot show a direct linkage.

What is becoming clear is that, if leadership training is to have a direct link with business outcomes, it should be linked with business performance metrics, not just outcomes, broadly defined. This point has been emphasized recently in a report by McKinsey which indicates that the training must incorporate key business performance metrics in order to have the effect that most organizations desire (Cermak J., McGurk M., 2010). In other words, traditional leadership training that, for example, focuses on interpersonal and social skills should also incorporate these issues in order to have maximum effectiveness.

Of course, this would require a major shift in curricula. But the weight of evidence is that even talk about business outcomes is not enough if the training and development does not also link directly to business and financial metrics which reflect the concerns of shareholders and investors as well as employees.

\section{But even behavioral disciplines need a killer app}

A while back I was discussing behavioral economics and finance with a very senior executive (British btw) for strategy and innovation in a well-known and respected global public company in the financial services space. He told me that his group had been carefully monitoring developments in these areas but so far they hadn't lived up to their billing. He and his colleagues still felt that the field was worth watching but they didn't see a killer app and couldn't see how it was going to help them in either the applied field of finance and economics, the core of their business, or even in the area of talent management.

My observation is that BE and BF have gotten more traction in the UK than in the US. But in the UK it's been mainly in the government, courtesy of the Nudge Unit set up under David Cameron. But it hasn't really gotten anywhere in the private sector in the UK, with some minor exceptions. On the other hand it has been aggressively picked up in the British universities.

It's a different story in the US. By and large the universities have ignored these areas. So has the government sector although there is a nascent unit in the White House. And the private sector, which leads just about everything in the US, hasn't picked it up at all save for some minor monitoring efforts in a few corporations. So in the US it's almost dead in the water with the education, public and private sectors.

But there is a funny thing going on in the US. In the popular imagination it's a big deal. That's especially because of the writings of Malcolm Gladwell and the newspaper columns by Daniel Kahneman. So in the US these fields have been adopted by the great unwashed and ignored by the literati in contrast to the situation in 
the UK where they have been promoted by the intellectuals and government and seemingly ignored by the common people.

Why the difference? In part it's been due to neocon influence from the Conservative Party and David Cameron's enthusiastic acceptance of the ideas in these fields. The vision is the potential for promoting real change in society and the economy by acting on behavior rather than on legislative fiat. In the US the neocon side has fallen into disfavor under the influence of a Democratic government which comes from a much more socially-oriented perspective.

But I think there's another factor at work. No-one (except Perth, see below) has yet created a killer app for BE and BF. It's a good theory and there's a lot of interesting work going on. This connects these fields to intriguing new areas in neuroscience, neuroeconomics and the like.

But how do you use it in practice? To get to the real point at least for the private sector, how do these fields help you make real money? So far that has been an elusive goal. The fact that the work has mainly been done by academics whose interest is intellectual rather than monetary (and mercenary) has added to the lack of interest from the private sector in both countries.

The behavioral theories, including those of economics and finance, remind me a lot of string theory. That's a popular new theory of physics that claims to unite the theories of relativity, quantum physics and gravity. That's the holy grail of physics and string theory seems to put it all together in a beautiful and elegant way.

There's only one problem though. There are no unique solutions to the equations of string theory. It gives rise to multiple dimensions, maybe 10 or 6 but we don't know coz the math breaks down. So although string theory provides searing and even jarring insights into the nature of reality, you cannot use it to figure out how to boil water for a mocha latte.

String theory has been developed by philosophers (pure mathematicians) for philosophers and has spawned a ferment amongst them. So far, though, the engineers aren't impressed because it does nothing for them. Until they can see a practical use they're going to stay on the sidelines.

I think that's what has happened in the behavioral strategy space. There some great insights and some of these can be used to create some new approaches to social problems. But for the private sector it does nothing to make it more money, solve macroeconomic crises, or predict which companies will fail or succeed. You cannot use it for derivatives and exotic synthetics or all the cutting edge finance stuff. Interesting yes, useful no.

My own company has, though, developed what we believe is the killer app. Our psychometric assessments predict whether individuals or teams will make money and also predict the enterprise valuation impact of these individuals and teams, even in quantitative terms.

But the government mandarins and academics who are trying to apply behavioral theories in the real world generally don't see the relevance of this work to the government sector and the private sectors have - so far been too hidebound to make any changes. That's despite the drubbing they received in the GFC and the problems that surfaced with their misuse - and sometimes abuse - of financial instruments such as ratings and derivatives.

The government and academics don't care about the money-making part so have ignored the financial aspects - including those that relate to the crucially important government fisc. The private sector - especially the financial services area - has recently been making money up the gazoo so they don't want to rock the money love-boat.

In addition the private sector mostly has a condescending view of behavioral theories- they see them as being imprecise and squishy, for softies and arts types, not for hard-headed business people. As a result they are missing out on the next revolution in behavioral finance - just like the governments are.

We see interest in the practical aspects of behavioral finance increasing rapidly. This article predicts that approaches such as ours will soon become leading models as the private sector finally recognizes it has a new tool that can address the problems that traditional economics and finance cannot. 


\section{Part 3: Financial Signature ${ }^{\circledR}$ is the key analytical construct}

\section{Financial Signatures ${ }^{\circledR}$ address atomism}

The Perth Leadership Outcome Model is so-called since it is concerned only with the outcome of behavior, not the behavior itself (Prince E. Ted, 2005). It defines outcomes in financial and valuation terms (Prince E. Ted, 2008). This model addresses both the issue of atomism and the issue of business outcome in a formal model that categorizes the types of financial behaviors and the financial and valuation outcomes that flow from the, without us knowing this.

The research is based on fieldwork with some several hundred CEOs and then with numerous other senior executives. It is based on the observation that we all have individual financial traits. These financial traits lie deep within us, so we shall call them innate. These financial traits constitute an internal calculus which drives how each of us approaches decisions involving risk and reward and cost and benefit. They imprint themselves on all of our decisions, in the vast majority of cases.

The research shows that there are distinct behavioral patterns, which reflect different ways that individuals are driven by these internal factors to create financial value. These behavior patterns are called Financial Signatures ${ }^{\circledR}$. The research has identified nine Financial Signatures ${ }^{\circledR}$ which we show below.

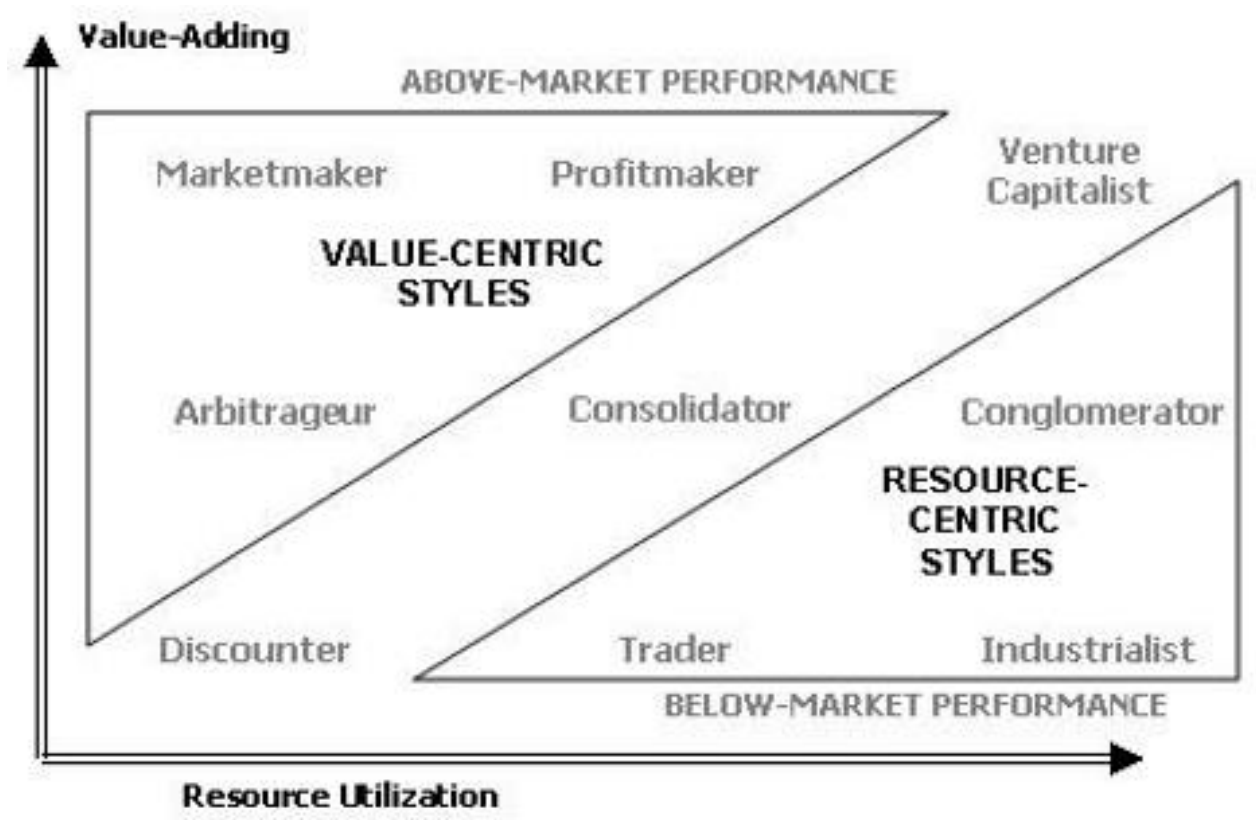

Figure 1. The Nine Financial Signatures ${ }^{\circledR}$

These financial behavior patterns, or Financial Signatures ${ }^{\circledR}$, are composed of two dimensions of financial traits. These are the propensity to utilize resources to a greater or lesser degree in achieving business goals, and the propensity to add commercial value to products or services, again in achieving business goals.

Each Financial Signature ${ }^{\circledR}$ is in effect a personalized and at least a partly irrational response to a financial situation which imposes a systematic and predictable bias on all of our financial decisions. Thus, individual behavior and individual cognitive effects have led the decision to be at least partly irrational in the particular manner which is dictated by the particular position that the manager occupies on the above diagram. Thus, the model is one that incorporates the cognitive biases of the individual concerning the factors of value-adding and resource utilization.

\section{And provide a formal model of business outcome}

The resulting Financial Signature ${ }^{\circledR}$ shows us the behavioral propensity of an individual to generate capital to a greater or lesser extent. In the diagram, Financial Signature ${ }^{\circledR} \mathrm{S}$ to the upper left generate more capital since their propensity to add relatively high amounts of value more than outweighs the resources they are behaviorally inclined to consume in achieving this value. 
On the other hand, on the right hand lower side of the diagram, individuals will be using a level of resources which generally will not be outweighed by the value-added contribution, which will lead to the generation of less or even the consumption of capital.

Financial Signatures ${ }^{\circledR}$ represent the most basic level of financial behavior. These can be grouped into styles which aggregate the signatures into a higher level representing the financial impact of these styles.

We can divide the nine Financial Signature ${ }^{R s}$ into three financial styles based on this diagram. These are the Value-Centric, Balanced and Resource-Centric styles. The first will tend to outperform the market and the last to under-perform while the balanced styles will perform at the market level.

Thus Financial Signature ${ }^{\circledR}$ and style can tell us not only about the level of individual performance we can expect, but what will happen if a company is composed mainly of a particular Financial Signature ${ }^{\circledR}$ or style relative to its close competitors and to the market it participates in as a whole. The Model is measurable in business terms.

Perth has developed instruments to identify and measure Financial Signature ${ }^{\circledR}$, most notably its Financial Outcome Assessment instrument. This has been given to almost 1,000 participants. Results show that most people cluster to the lower right of the Financial Signature ${ }^{\circledR}$ chart.

Most managers have Financial Signature ${ }^{\circledR} \mathrm{s}$ that leads them to under-perform the market and either to generate less capital than their close competitors or to consume it. This pattern prevails even at high executive levels and so far the research has not been able to find a statistical difference in Financial Signature ${ }^{\circledR}$ between executives and other levels.

This parallels work done in other leadership studies which shows that on both personality and competency tests, there are no significant differences between managers at widely different levels (Hogan Robert, 2006). It also provides a more scientific underpinning for studies that show that few leaders consistently make money and that the vast majority fail as leaders, on both straight leadership and financial results grounds (Hogan Robert, 2006).

The value-added dimension of financial style is reflected in the gross margin of a unit or enterprise relative to other similar units or close competitors.

\section{Behavioral ratings for public and private equity}

That is, this accounting measure is a true measure of value-added, both at a corporate and at a behavioral level. We use this measure and not profitability since the latter does not measure value-added. It was not designed to do so, and in any case is too prone to manipulation to be useful.

Similarly the resource utilization dimension of financial style is reflected in the level of indirect expenses relative to other units doing similar work or to close competitors. Once again we need to convert this to a percentage of revenue to allow comparison with other units in the organization and with close competitors.

By adopting this approach, we can calculate the financial mission of the unit or enterprise and compare it to its competitors. This will show the relative positions of the enterprises in a market from the viewpoint of their financial mission.

If Financial Signature ${ }^{\circledR}$ leads to a systematic bias to financial decisions either by individuals or teams; we would expect this to be reflected in the valuation of a company. Our original research found such an impact. Basically the Value-Centric financial styles lead to relatively high growth and high capital generation over the longer-term, since the value- added impact of the style more than outweighs the resources utilized in its achievement. The reverse is true for the Resource-Centric styles which lead to relatively low growth over the longer-term and thus relatively low or negative capital generation. 


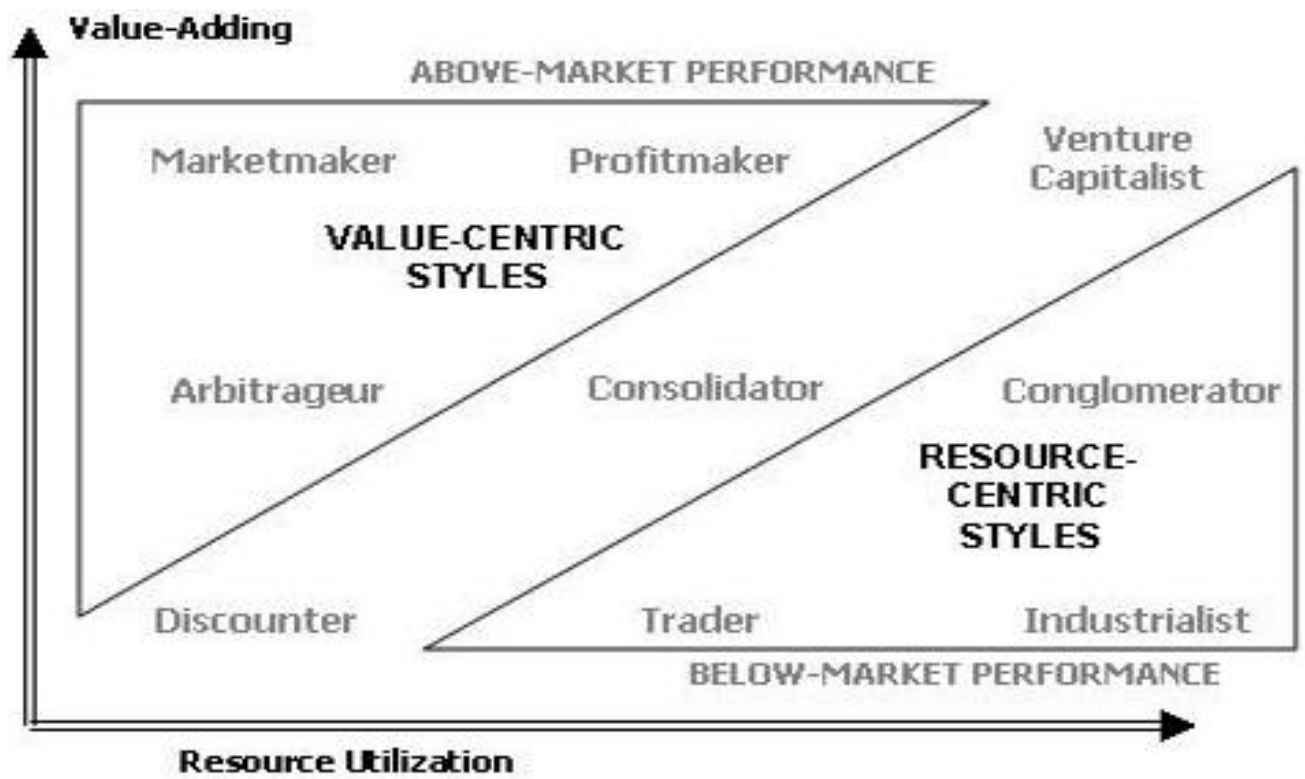

Figure 2. The Nine Valuation Trajectories

The Perth model addresses corporate and microeconomic issues and decision-making via the concept of the Financial Signature ${ }^{\circledR}$ and the associated valuation outcome. It addresses macro-economic and regional and national decision-making via the aggregation of these signatures at the appropriate social levels. The cognitive biases it addresses can be measured both psychometrically through assessments and financially as reflected in the financial statements of a company.

The Perth approach does takes behavioral finance a major step forward by enabling prediction to be carried out at the level of a specific individual, team or company and to predict the precise financial and valuation outcomes that will flow from these decisions. The approach is measurable and able to be operationalized so that it provides results that can be falsified, the major criterion of a scientific method.

\section{Providing an atomistic-outcome behavioral synthesis}

The Perth model is strictly concerned with business outcomes. They must be measured in terms of their value and valuation impact. Leadership only has an impact if it impacts business outcomes. Anything else may be a valuable outcome but unless it impacts organizational value and valuation measured in financial terms, it is not a criterion for deciding if leadership has been successful or not.

The Perth model leads to a new type of synthesis between behavior, business outcomes and leadership. This results in the following principles:

Leadership is valuation: we can only measure leadership through its results; leadership can only be said to be successful if the valuation of the unit, team or enterprise increases relative to its competitors.

Valuation is outcome: In any organization, its valuation relative to its competitors drives its outcome. This valuation may be measured in financial or non-financial terms both quantitative and qualitative, such as in nonprofits or a governmental organization.

Valuation is behavior: Valuation is not profitability, assets, sales or intellectual property; these are merely symptoms of behavior. The financial metrics which measure these quantities are merely measuring the results of behavior and they should not be confused with behavior or valuation itself.

All employees have a virtual $P \& L$ : every employee contributes to the valuation of an enterprise, even if they are not aware of that fact. Each of them has a virtual P\&L, whether or not it is recorded. The job of all employees is to increase their own virtual P\&L so that they increase the valuation of their unit, team or enterprise.

All decisions have a value impact: Even if the decision is not explicitly financial in nature, it will have a value impact since it comprises two drivers, value-adding and resource utilization. These may be measured in financial or objective or in qualitative or non-financial terms. 


\section{The Financial Signature ${ }^{\circledR}$ solution}

The Perth Leadership Institute has developed an outcome-based leadership theory. This is called the Perth Leadership Outcome Model (PLOM). This model has been developed according to the principles set out in the preceding sections. PLOM is based on a totally new paradigm for leadership assessment and development.

In the Perth model, a leader is not assessed in terms of his or her capabilities. Instead, they are assessed only in terms of their impact on the outcome of the enterprise they lead. In the Perth model, the ultimate form of outcome is valuation. A leader has succeeded if valuation increases and fails if it has decreased both over the longer - term.

Valuation is not just a financial issue. At the very least, valuation captures how the market views the company from the viewpoint of its viability and the probability of a positive financial outcome. Thus at the very least we can use valuation as a proxy for the sustainability of the company and its value in the market.

But there are broader applications. These include showing to a leader, a board, investors, or even recruiters, the potential company valuation outcome of recruiting a particular leader, or a particular type of leader.

\section{Part 4: Leading to practical business cycle prediction products}

\section{Behavioral risk varies with the business cycle}

Hyman Minsky predicted in his work several decades ago that business recessions are an inevitable occurrence and driven by human nature (Hyman Minsky). As the market becomes hotter, the level of risk taken by both companies and individuals moves to increasingly high levels. As market returns increase, more marginal players are drawn in who take even greater risks. At some stage there is a correction, the market shakes out and is reduced to the strongest players. Then the whole process starts again.

It is clear that this process is closely related to the levels of business acumen. As markets become hotter, they increasingly draw in players who have less or no business acumen and take more risk. These players are not just private individuals and consumers. They are also corporate managers, executives and CEOs as well as those formally having the responsibility to assess and predict market risk.

A rising tide lifts all boats and so corporate managers increasingly feel that it is their skill that has driven their success rather than market factors. At its peak, the market has the lowest level of players, both individual and managerial, from the perspective of their business acumen. At this point, market risk is at its highest and the number of players with high levels of business acumen is proportionately at its lowest.

Once the market shakes out and reaches its lowest level, the aggregate amount of business acumen of the players is proportionately at its highest level and therefore market risk is at its lowest level. At this point the process of introduction of players with much less business acumen starts all over again.

Thus, we can see that the level of business acumen varies directly with the market cycle. As the cycle builds to higher levels, there will be more players with low levels of business acumen entering the markets. These players will still appear to be very successful and they will incorrectly attribute their success to their own skills and business acumen instead of market factors. Once the correction comes, they will be shocked by the turnaround and their own demise.

This process does not differentiate between players, including executives and managers, who have high levels of business learning, business education and technical skills. Only those who have relatively high levels of business acumen and those directly associated with them will be spared.

Indeed, the process will actually tend to lead to even higher levels of risk-taking amongst these groups since they wrongly assume that their market successes derive from these factors (business education, business learning and technical skills). So these groups will tend to take even more risk because they feel they are protected by their own business education and technical skills. Such groups will therefore have even higher impact failures than other groups who do not possess appropriate levels of business acumen.

These processes are sustained and amplified by group behavior in which peers watch the successes of their colleagues and are driven to take even greater risks because of competitive and peer pressures and also because of the importance of image to their market branding. 
Leadership development models such as the Boffin model that are centralized and focus on technical skills will therefore tend to exacerbate these problems by going along with these assumptions. Thus, leadership development programs will usually become part of the problem by adding even more to group pressure and by supporting a centralized model which in fact exacerbates aggregate market risk.

\section{Financial Signature ${ }^{\circledR}$ is the critical metric in judging the business cycle}

We can now see that we can translate the term "business acumen" into "financial signature ${ }^{\circledR}$ ". This gives us a way of approaching business cycles based on the extent to which there are different proportions of different types of financial signature in the business population. In fact we can now say that is the proportion of valuecentric to resource-centric signatures in the business population is the critical metric for identifying which part of the business cycle we are in currently and when a recession is likely to occur.

The critical metric is the level of resource utilization to the level of value-adding. When this metric is high, the proportion of expense to resource utilization-focused behaviors in the company and business population will be at a high. What this means is that the proportion of people in the business population with high levels of resource-centric behaviors in historically high relatively to this with high value-centric-focused behaviors.

However, we need to take into account historical norms. We know from our own testing that historically on average around $88 \%$ of this population have resource-centric behaviors. That means it is normal for most people to have resource-centric behaviors. We should be looking for this level to become a lot higher, assay around $95 \%$ or more. This occurs as the business cycle moves into a situation of irrational exuberance where business acumen is no longer important in business and where people who have low business acumen are accepted and extolled and take ever-great risks.

At the diagram below Figure 3 Financial Signature Metric During the Business Cycle we have depicted a model of this business acumen trajectory over the business cycle. We have mapped it for a typical business cycle. At the following diagram Figure 4 Recent Business Cycles, we have mapped the level of business acumen to the time period 1990 to the present time.

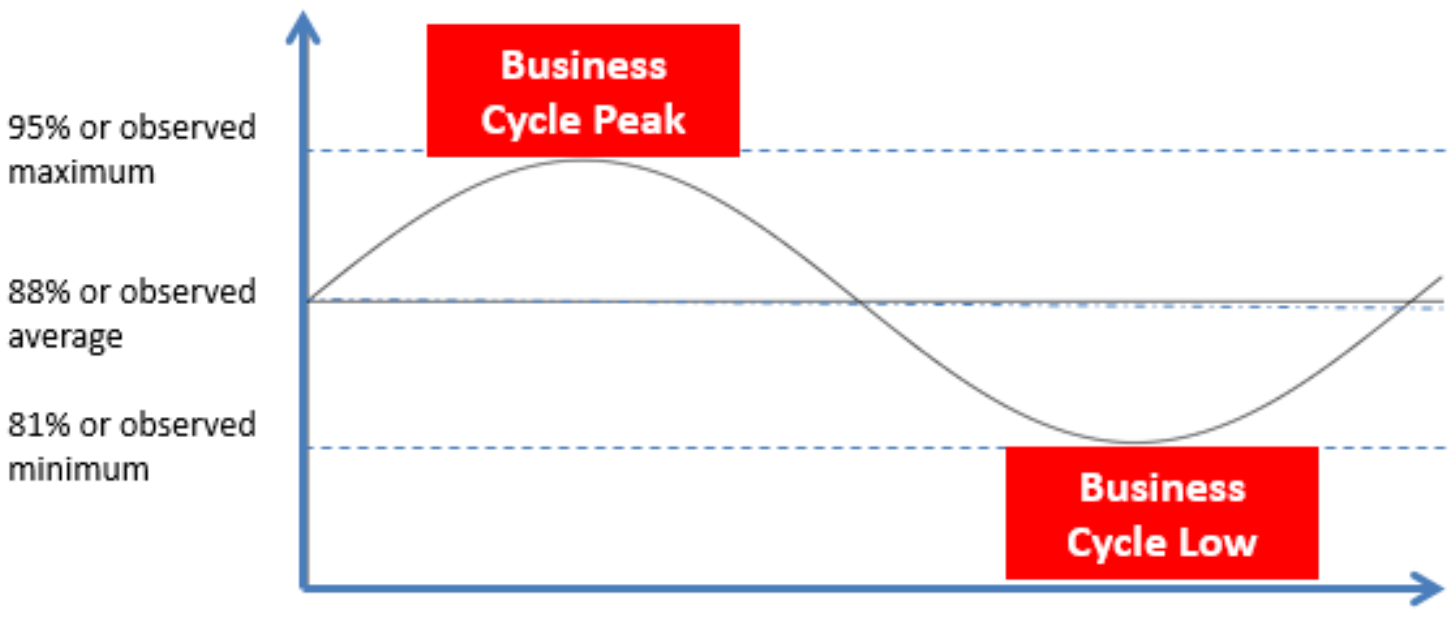

Figure 3. Financial Signature Metric During the Business Cycle

Note that when we use the figures of $88 \%$ as an average for the financial signature metric for resource-centric levels, and 95 for the tripwire level for recession we are giving averages for the US section. These figures will vary by country, industry and city. There will be a range of such levels that each vary around a local or global average and around the tripwire metric. These actual values will need to be established as to their current and long-term averages and for the current values for each level of aggregation we are tracking presently. 


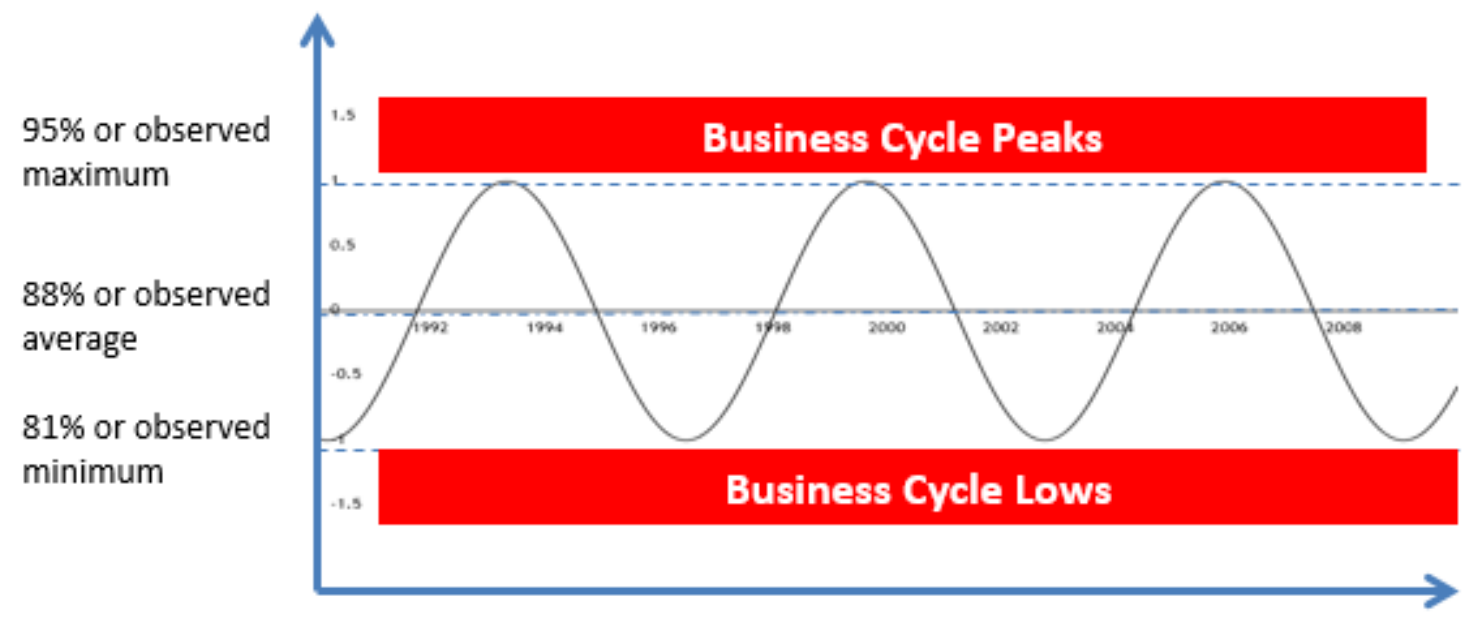

Figure 4. Recent Business Cycles

We can see that when we use financial signature to show the stage of the business cycle we are not using macroeconomic aggregates such as GDP growth or industrial production. It is well- known that these are lagging indicators and unreliable indicators of the stage of the business cycle. This is why the record of forecasting is so poor. Instead we are using behavior. This is a leading indicator. It is behavior that comes first and then impacts financial aggregates that eventually show up in macroeconomic data. Thus by using financial signature as a predictive metric we are switching from the use of a lagging indicator which has been demonstrated to not be able to give accurate results to one which will give accurate results.

\section{The products}

There are three possible ways to collect the information. All three ways are based on using the framework of the financial signature and the Financial Outcome Assessment, which is used to measure this behavior. However it should be noted that it is not necessary to assess selected participants in a survey by direct assessment although this approach can be used. It is also possible to use assessors who have bene trained in the methodology and who are trained to ask particular questions and to code the responses according to the specialized framework of the financial signature approach.

The three ways of collecting this information are:

Behavioral ratings;

Regular survey;

Crowdsourcing.

\section{Behavioral ratings}

It would be possible to set up a company to develop a system of behavioural ratings for use by analysts to assess the likely future financial performance of companies, based not on traditional company financial metrics but on behavioral data which is used to predict profitability and valuation of the company based on the behaviors of the leaders and senior management team.

The main objective of behavioral ratings is a microeconomic tool to help investors and analysts forecast the future performance of the company. However since the data is already being collected for microeconomic purposes it would be a relatively easy matter to also use the data to construct times series of the ratings of individual leaders and teams categorized by location, time and industry. This would result in a time-series of the appropriate and relevant data being collected which could be used for the macroeconomic purpose of identifying the stage of the business cycle.

\section{Regular behavioral surveys}

The data could also be collected by regular demographic surveys of the relevant groups by agents whose only purpose is to collect this data for macroeconomic purposes. This would be similar in concept to the Michigan Survey of Consumer Confidence. Indeed the survey is essentially one of business person confidence. The difference is that it is aimed only at senior business people and is constructed according to a framework that links directly back to the financial outcomes of financial behaviors by decision-makers in the private sector. 


\section{Crowdsourcing}

This is another approach. This could be done by setting up a special website where business people are registered according to a self-selection approach and opt to do an assessment which provides the necessary data based on the financial signature ${ }^{\circledR}$ approach. In order to counter the bias introduced by self-selection the site would have to utilize special algorithms to smooth out the data and process it into forms which remove the biases and normalize the data. This approach would be the cheapest but would require more work to set up since it is essentially algorithmic in nature and these algorithms have yet to be developed.

\section{Predicting recessions and the business cycle}

This article explains business cycles by the level of business acumen in the business marketplace. In other words, it's a behavioral phenomenon. Just as Keynes said, it is animal spirits, the particular level of mixed rationality that prevails at that particular time.

Using the financial signature ${ }^{\circledR}$ model we can measure these levels. If they are done consistently over time, just like consumer surveys are now, we can track the business cycle precisely. We are going to be able to tell when a recession is about to hit.

The organizations to conduct this could be the government itself, economics institutes, central banks, or private businesses. These days these surveys could be done much more quickly and easily by using the numerous internet means, apps and crowdsourcing websites.

\section{Conclusions}

This paper sets out a radical new approach to the identification and analysis of the business cycle. It is a behavioral rather than a strict "economic" approach and it adopts new concepts related to cognitive biases that have not been used in this way before. So it is natural that most economists will have at best a quizzical view of the approach.

Current financial prediction and ratings approaches failed to prevent the last economic crisis. They have exhausted analysts' imagination and creativity at devising new ways to predict recessions and the current stage of the business cycle. This has occurred because current economic theory has two basic and fundamental flaws. These are:

$>$ It assumes that economic decisions are made on rational grounds;

$>$ It does not take into account the cognitive biases of economic actors, including those of consumers, investors and managers.

Since the early 2000s a new approach to economics and finance has emerged. This is called behavioral economics and finance. This addresses directly the problems of traditional economics and finance. Thus, the new disciplines drop the assumption of complete rationality in favor of the assumption of mixed rationality, that is, economic decisions are made on the basis of both rational and non-rational concerns. The new disciplines have identified the main cognitive biases that make decisions non-rational and show how they impact economic and financial outcomes.

However even these new disciplines have not addressed all the issues. The main problem with them is that they do not have a rigorous way of identifying the cognitive biases of specific individuals and teams. So in general we can address what type of biases consumers, investors and managers might have, but we don't know in any given and specific case exactly what these biases are.

Second, even if we knew the specific biases, these disciplines do not provide any way of rigorously linking them to specific economic and financial outcomes. By "specific" we mean the ability to precisely predict the quantitative impact on both national accounts and corporate financial statements. So these disciplines provide a new theoretical framework but they don't allow us to take that any further to make exact financial and economic predictions. Thus they are still theoretical disciplines only.

The paper introduces a new construct that can be measured psychometrically. It's called Financial Signature ${ }^{\circledR}$. This behavior can be measured and linked directly to financial and valuation outcomes. It's the missing link in business cycle prediction.

This paper sets out a new approach which addresses both the problem of precise identification of a person or a team's cognitive biases in terms that can qualitatively demonstrate the exact kinds of economic and financial impact they will have. The paper also shows how these cognitive biases can be linked to financial outcomes 
in the same quantitative terms used in the production of a company's normal financial statements. The approach will therefore enable predictions to be made about the impact on metrics such as revenues, gross margin, expenses and operating profit. This is a radical new approach which extends the power of the new disciplines in a major way. Thus the approach provides a new approach at the microeconomic level.

Using this model we can also use the model to predict the impact of cognitive biases on the business cycle. We can do this by showing how the business cycle is driven by the changing proportions of economic actors with different cognitive biases. Thus the approach can also be used to predict the macroeconomic impacts of cognitive biases thus providing a new lens for viewing the business cycle. This yields an answer to predicting why and how recessions get started and end, using a purely behavioral approach.

Using this framework we can implement practical behavioral finance products that for the first time provide a direct link between leaders, management teams and business cycle prediction. This solves the problems inherent in current economics and in business cycle analytical approaches.

\section{References}

1. Bertrand, Marianne and Scholar, Antoinette (2003). Managing with Style: The Effect of Managers on Firm Policies. Quarterly Journal of Economics, 118(4), 1169-208.

2. Cermak, J., McGurk, M. (2010). Putting a Value on Training. McKinsey Quarterly.

3. Cronqvist, H, Makhija, A. K., Scott E. Yonker, S.E. (2010). Behavioral Consistency in Corporate Finance: CEO Personal and Corporate Leverage. Available at http://74.125.155.132/scholar?q=cache:yO5GnN9KuNoJ:scholar.google.com/\&hl=en\&as_sdt=40005\&sc iodt $=40000$.

4. Goldsmith, Marshall and Reiter, Mark (2007). What Got You Here Won't Get You There. Hyperion; ISBN: 1401301304, Available at http://www.marshallgoldsmithlibrary.com/cim/What-Got-YouHere.php.

5. Hogan, Robert (2006). Personality and the Fate of Organizations. New Jersey: Lawrence Erlbaum, p. 41; 206.

6. Hyman Minsky. Stabilizing an Unstable Economy 1st Edition. Available at http://www.amazon.com/Stabilizing- Unstable-Economy-Hyman-Minsky/dp/0071592997.

7. Lovallo, Dan and Sibony, Olivier (2010). The case for behavioral strategy. McKinsey Quarterly. Available at http://www.mckinsey.com/business-functions/strategy-and-corporate-finance/our-insights/the-case-forbehavioral-strategy.

8. Lucier, C., Kocourek, P. and Habbel, R. (2005). CEO succession 2005. The crest of the wave. 2006. Strategy and Business, Summer, pp. 100-113. 808 NW $13^{\text {th }}$ St.

9. Prince, E. Ted (2005). The Three Financial Styles of Very Successful Leaders, McGraw-Hill, New York.

10.Prince, E. Ted (2008). Research Note: How the Financial Styles of Managers Impact Financial and Valuation Metrics. Review of Accounting and Finance, 7(2), 193-205.

11.Taleb, Nasim. The Black Swan: Second Edition: The Impact of the Highly Improbable Fragility. Available at http://www.amazon.com/The-Black-Swan-Improbable-Fragility-ebook/dp/B00139XTG4.

12. Zagorsky, Jay (2007). Do you have to be smart to be rich? The impact of IQ on wealth, income and financial distress. Article in Intelligence, 35(5), 489-501. Available at https://www.researchgate.net/publication/222681959_Do_you_have_to_be_smart_to_be_rich_The_impa ct_of_IQ_on_wealth_income_and_financial_distress. 